\title{
Dampak Implementasi Jaminan Kesehatan Nasional terhadap Ketersediaan Obat di Apotek Rujukan Wilayah Cibeunying Kotamadya Bandung Tahun 2015
}

\author{
Algiza Gauthfa, ${ }^{1}$ Kuswinarti, ${ }^{2}$ Deni Kurniadi Sunjaya, ${ }^{3}$ \\ ${ }^{1}$ Fakultas Kedokteran Universitas Padjadjaran, \\ ${ }^{2}$ Departemen Farmakologi dan Terapi, Fakultas Kedokteran, Universitas Padjadjaran, \\ ${ }^{3}$ Departemen Ilmu Kesehatan Masyarakat, Fakultas Kedokteran, Universitas Padjadjaran
}

\begin{abstract}
Abstrak
Tahun 2014 Pemerintah Indonesia melakukan perubahan sistem pembiayaan kesehatan yang disebut dengan Jaminan Kesehatan Nasional. Salah satu faktor penting yang harus diperhatikan untuk mencapai tujuan Jaminan Kesehatan Nasional adalah ketersediaan obat. Penelitian ini bertujuan untuk mengidentifikasi dan mengeksplorasi dampak perubahan sistem pembiayaan kesehatan terhadap ketersediaan obat Jaminan Kesehatan Nasional di apotek rujukan. Penelitian ini menggunakan metode kualitatif dengan pendekatan grounded theory. Pengambilan data menggunakan wawancara mendalam terhadap 8 informan yang dianggap memiliki pengalaman dalam perubahan sistem pembiayaan kesehatan. Penelitian ini dilakukan pada bulan Maret-Desember tahun 2015. Tempat yang dijadikan objek penelitian adalah 2 apotek di Wilayah Cibeunying Kotamadya Bandung. Perubahan pembiayaan kesehatan berdampak pada 4 aspek, yaitu: regulasi terkait obat; manajemen apotek dan BPJS Kesehatan; penyediaan obat; dan permintaan obat. Keempat hal tersebut kemudian berdampak kepada ketersediaan obat, yang akan mempengaruhi: kepuasan peserta Jaminan Kesehatan Nasional dan apotek; dan keuntungan apotek. Perubahan sistem pembiayaan kesehatan dapat berdampak pada apotek yang belum disiapkan untuk berubah. Apotek akan mampu beradaptasi apabila memiliki komitmen untuk terus belajar dan memiliki sumber daya yang memadai. Kesimpulan, Dampak dari perubahan sistem pembiayaan kesehatan perlu disertai dengan kesiapan sektor pemerintah maupun swasta.
\end{abstract}

Kata kunci: Apotek, Jaminan Kesehatan Nasional, obat, sistem kesehatan

\section{Impact implementation of Jaminan Kesehatan Nasional to drugs availability at Pharmacy Referral in Cibeunying Region Bandung 2015}

\begin{abstract}
In 2014 the Government of Indonesia implemented a new health financing system, called Jaminan Kesehatan Nasional. One important factor that must be considered to achieve the objectives of the Jaminan Kesehatan Nasional is the availability of drugs. This study aims to identify and explore the impact of changes in health financing system to the Jaminan Kesehatan Nasional drugs availability in pharmacies. This study design used a qualitative method with a grounded theory approach. In-depth interview was applied to 8 informants who are considered to have experience in the health financing system changes. This study conducted in March-December 2015 at 2 pharmacies located in Cibeunying Region Bandung City. The results showed that changes in health financing system have an impact on four major aspects: drug-related regulations; management of pharmacy and BPJS Kesehatan; supply of drugs; and demand of drugs. These fourth aspects will affect; the satisfaction of Jaminan Kesehatan Nasional's participants and pharmacies; and pharmacy's profit margin. Changes in health financing system can impact pharmacies that have not prepared for the change. Pharmacies will be able to adapt if it is committed to learn and have adequate resources. The impact of changes in health funding system needs to be accompanied by the readiness of the Government and the private sector.
\end{abstract}

Keywords: Drugs, health system, Jaminan Kesehatan Nasional, National Health Insurance, pharmacy

Korespondensi:

Algiza Gauthfa

Fakultas Kedokteran Universitas Padjadjaran

Jalan : Prof. Eyckman No.38 Bandung 40161

Mobile : 085794738273

Email : gizagauthfa@gmail.com 


\section{Pendahuluan}

Pemerintah negara Republik Indonesia pada bulan Januari tahun 2014 melakukan sebuah transformasi pada sistem kesehatan di Indonesia dengan mulai diselenggarakannya program Jaminan Kesehatan Nasional (JKN). Jaminan Kesehatan Nasional merupakan sebuah program pemerintah yang terdapat dalam program Sistem Jaminan Sosial Nasional (SJSN) dan merupakan implementasi dari Universal Health Coverage. Program JKN bertujuan untuk memberikan jaminan manfaat pemeliharaan kesehatan dan perlindungan finansial bagi pesertanya. Hal yang dicakup oleh JKN merupakan manfaat promotif, preventif, kuratif, dan rehabilitatif termasuk pelayanan obat dan bahan medis habis pakai sesuai dengan kebutuhan medis. ${ }^{\text {}}$ Obat-obatan menjadi salah satu faktor penting yang harus diperhatikan dalam rangka mencapai tujuan JKN. Penyediaan obat dalam JKN telah diatur dalam Formularium Nasional (Fornas) yang merupakan daftar obat-obatan yang disusun oleh Komite Nasional (Komnas) Penyusunan Fornas. Fornas berfungsi sebagai pedoman bagi penyedia layanan kesehatan untuk menyediakan obat-obatan yang terjamin mutu, aman, dan terjangkau sehingga dapat meningkatkan standar mutu pelayanan dalam JKN. Program JKN dalam pelaksanaannya melibatkan pihak pemerintah dan swasta. Salah satu pihak swasta yang tergabung dalam program ini adalah apotek swasta yang menjadi apotek rujukan. Sampai saat ini dampak perubahan sistem pembiayaan kesehatan ketersediaan obat-obatan terpilih Fornas pada apotek rujukan masih belum diketahui. Artikel di media massa bahkan mengeluhkan bahwa penyediaan obat dalam program JKN dinilai mengecewakan, terlebih bagi pasien penderita penyakit kronis. ${ }^{2}$
Berdasarkan uraian di atas, peneliti melakukan penelitian yang bertujuan untuk mengetahui dan mengeksplorasi dampak perubahan sistem pembiayaan kesehatan terhadap ketersediaan obat terpilih pada era Jaminan Kesehatan Nasional di apotek rujukan wilayah Cibeunying Kotamadya Bandung.

\section{Metode}

Penelitian ini dilakukan pada bulan MaretDesember tahun 2015. Tempat penelitian di wilayah Cibeunying Kotamadya Bandung karena ini merupakan penelitian multi senter. Diwilayah ini terdapat 2 apotek yang dijadikan objek penelitian yaitu 1 apotek yang masih bekerjasama dengan BPJS Kesehatan dan 1 apotek yang pernah bekerjasama dengan BPJS Kesehatan tetapi kemudian memutuskan untuk tidak melanjutkan kerjasama tersebut. Penelitian ini menggunakan metode deskriptif kualitatif dengan pendekatan induktif. Teknik pengambilan data dilakukan dengan wawancara mendalam terhadap subjek penelitian.

Instrumen yang digunakan dalam penelitian adalah pedoman wawancara mendalam. Subjek penelitian terdiri dari 8 informan yang dianggap memiliki pengalaman dalam perubahan sistem pembiayaan kesehatan, yaitu apoteker, asisten apoteker, administrasi apotek, peserta BPJS Kesehatan yang pernah menjadi peserta Askes, peserta BPJS Kesehatan yang tidak pernah menjadi peserta Askes, apoteker apotek yang berhenti bekerjasama dengan BPJS Kesehatan, asisten apoteker apotek yang berhenti bekerjasama dengan BPJS Kesehatan, dan pihak BPJS Kesehatan Kota Bandung. Metode yang digunakan dalam menentukan subjek penelitian

Tabel 1 Kriteria Inklusi dan Eksklusi Subjek Penelitian

\begin{tabular}{|c|c|c|}
\hline Subjek Penelitian & Kriteria Inklusi & Kriteria Eksklusi \\
\hline $\begin{array}{l}\text { Apoteker, Asisten Apoteker, dan } \\
\text { petugas administrasi Apotek } \\
\text { Rujukan }\end{array}$ & $\begin{array}{l}\text { Masih terdaftar sebagai pegawai } \\
\text { tetap }\end{array}$ & Menolak mengikuti penelitian \\
\hline $\begin{array}{l}\text { Apoteker dan Asisten Apoteker } \\
\text { Apotek Non BPJS }\end{array}$ & $\begin{array}{l}\text { Pernah bekerja pada saat } \\
\text { apotekmasih bekerjasama dengan } \\
\text { BPJS }\end{array}$ & Menolak mengikuti penelitian \\
\hline Peserta BPJS Non Askes & $\begin{array}{l}\text { Belum pernah menjadi peserta } \\
\text { Askes }\end{array}$ & Menolak mengikuti penelitian \\
\hline Peserta BPJS dari Askes & $\begin{array}{l}\text { Masih terdaftar sebagai peserta } \\
\text { BPJS } \\
\text { Pernah menjadi peserta Askes }\end{array}$ & Menolak mengikuti penelitian \\
\hline Petugas BPJS Kota Bandung & $\begin{array}{l}\text { Masih terdaftar sebagai petugas } \\
\text { BPJS kota Bandung }\end{array}$ & Menolak mengikuti penelitian \\
\hline
\end{tabular}


adalah purposive sampling. Beberapa kriteria yang harus dipenuhi untuk menjamin kepercayaan (trustworthiness) dalam penelitian kualitatif, yaitu kredibilitas (credibility), transferabilitas (transferability), dependabilitas (dependability), dan konfirmabilitas (confirmability) ${ }^{3}$. Untuk menjamin kredibilitas penelitian, peneliti melakukan pengujian kredibilitas dengan cara melakukan triangulasi sumber data (data source triangulation) dan member checking. Kemudian untuk menjamin transferabilitas dalam penelitian, peneliti menjelaskan hasil wawancara dengan deskripsi mendetil agar dapat dibandingkan dengan fenomena yang ada. Untuk menjamin dependabilitas dalam penelitian ini peneliti menjelaskan secara mendalam metode yang digunakan dalam penelitian, sehingga memungkinkan penelitian untuk dilakukan kembali di masa mendatang. Kemudian, untuk menjamin konfirmabilitas dalam penelitian ini peneliti melakukan triangulasi dan audit terhadap proses penelitian. Proses yang diaudit dalam penelitian ini dimulai dari pengambilan data sampai dengan penarikan kesimpulan.

Penelitian ini telah disetujui oleh Komisi Etik Fakultas Kedokteran Universitas Padjadjaran.

\section{Hasil}

Data hasil wawancara terhadap beberapa subjek dianalisis dengan menggunakan teknik koding terbuka dan digunakan kategori-kategori untuk menjelaskan mengenai dampak perubahan sistem pembiayaan kesehatan terhadap ketersediaan obat Jaminan Kesehatan Nasional di apotek rujukan wilayah Cibeunying Kotamadya Bandung.

Hasil wawancara informan dikelompokkan menjadi 2 kategori, yaitu: Dampak perubahan sistem pembiayaan; Dampak ketersediaan obat. Kategori tersebut kemudian dapat diuraikan menjadi tema-tema, yaitu: Dampak perubahan sistem pembiayaan kesehatan: regulasi terkait obat, manajemen pihak-pihak terkait, penyediaan obat, dan permintaan obat; Dampak ketersediaan obat: kepuasaan peserta dan apotek serta keuntungan yang didapatkan oleh apotek.

Pelaksanaan perubahan sistem pembiayaan kesehatan secara otomatis mengubah sistem regulasi pengadaan obat di apotek yang tergabung dalam BPJS Kesehatan. Apotek melakukan pembelianobatpadadistributorobatatauPedagang Besar Farmasi (PBF) yang telah bekerjasama dengan BPJS Kesehatan melalui e-catalogue.

Harga yang disepakati antara PBF dan BPJS Kesehatan jauh lebih murah dibandingkan dengan harga Askes atau harga umum, sehingga seharusnya apotek dapat menghasilkan keuntungan yang lebih dari harga obat, namun praktik di lapangan tidaklah demikian. Terjadi mismatching antara harga obat yang disepakati oleh PBF dan BPJS Kesehatan dengan harga obat yang dijual oleh PBF ke apotek. Hal tersebut berimbas terhadap jumlah nilai (harga) klaim yang tidak sesuai, karena BPJS Kesehatan menetapkan harga klaim menggunakan e-catalogue sedangkan apotek melakukan pembelian dengan harga Askes atau harga normal, sehingga terjadilah kerugian pada saat melakukan klaim. Masalah selanjutnya terkait regulasi obat adalah mengenai persyaratan mendapatkan obat. Di dalam JKN, terdapat obat-obat yang peresepannya harus disertai pemeriksaan penunjang misalnya hasil pemeriksaan laboratorium, namun seringkali informasimengenai syarat-syarat yang dibutuhkan untuk peresepan obat terlambat sampai ke apotek agar selanjutnya dapat diklaim oleh apotek, Keterlambatan informasi tersebut sering terjadi bahkan mencapai 20 hari kerja sehingga obat-obat yang sudah terlanjur diberikan kepada pasen tidak dapat di klaim dan menimbulkan kerugian apotek karena tidak adanya pemeriksaan penunjang. Hal inilah yang terjadi pada apotek yang berdampak pada pemutusan kerja sama dengan BPJS karena menderita kerugian yang cukup besar.

Dampak selanjutnya yang ditimbulkan oleh perubahan sistem pembiayaan kesehatan terjadi pada manajemen pihak-pihak yang terkait dengan penyediaan obat di apotek. Dengan berubahnya sistem pembiayaan kesehatan, maka terjadi juga perubahan-perubahan di tingkat manajerial guna menyesuaikan dengan perubahan yang ada. Namun, pada kenyataannya, pihak-pihak yang terkait di antaranya adalah BPJS Kesehatan, Industri Farmasi pemenang tender penyedia obat dan distributor (PBF) dan apotek terkesan lambat dalam beradaptasi terhadap perubahan yang ada.

Dalam penyediaan obat berdasarkan fornas ini makamekanismepengadaanobatolehapotek dapat melalui e-purchasing berdasarkan e-catalogue. Apabila pengadaan obat melalui e-purchasing berdasarkan e-catalogue ini mengalami kendala operasional dalam aplikasi, pembelian dapat dilaksanakan secara manual. Pembelian manual dilaksanakan secara langsung kepada Industri Farmasi yang tercantum dalam katalog elektronik (e-catalogue). Apotek Jejaring/rujukan atau apotek yang bekerja sama dengan BPJS dapat melayani pelayanan obat untuk fasilitas kesehatan tingkat pertama, yaitu untuk keperluan di klinik apabila klinik tidak memiliki apoteker. Selain itu juga melayani untuk praktek dokter, dokter gigi, dokter spesialis dan dokter gigi spesialis layanan primer. Penyediaan obat untuk praktek dokter ini mengacu kepada fornas yang dilaksanakan oleh apotek sebagai jejaring pelayanan kesehatan. 
Untuk fasilitas kesehatan tingkat kedua dan ketiga di rumah sakit penyediaan obat dilaksanakan oleh Instalasi Farmasi Rumah Sakit melalui e-catalogue. Dalam pelaksanaannya, di tingkat fasilitas kesehatan tingkat ketiga di Rumah Sakit, Instalasi Farmasi Rumah Sakit hanya memberikan obat untuk 7 hari yang diresepkan, sedangkan yang 23 hari diambil di apotek jejaring.

Dari hasil wawancara dengan petugas apotek didapat informasi bahwa BPJS Kesehatan sebagai penyelenggara JKN kurang sigap/ cepat dalam memberikan informasi-informasi terkait program JKN kepada pelaksana program. Selain itu BPJS sentral di rumah sakit yang bertugas untuk melakukan verifikasi, elijibilitas terhadap resep obat (jenis dan jumlah obat) kadangkala tidak teliti ketika memberikan persetujuannya sehingga berdampak pada kekecewaan pasien karena tidak diberikannya obat yang diresepkan dokter oleh apotek.

Perubahan sistem pembiayaan juga memberikan dampak terhadap manajemen apotek. Perubahan manajemen yang terjadi adalah penyiapan modal dan penyediaan jumlah obat. Terjadi peningkatan mencapai 3x lipat dalam modal yang disiapkan apotek untuk bergabung dalam JKN. Salah satu penyebab utama peningkatan modal tersebut adalah untuk mempersiapkan ketika terjadi keterlambatan proses pembayaran klaim dari BPJS Kesehatan yang kerap terjadi. Hal ini merupakan sebuah masalah besar ketika apotek yang bekerjasama tidak memiliki modal yang cukup besar. Untuk menyiasati hal tersebut, pelanggaran peraturan terkadang dilakukan apotek guna menanggulangi kerugian yang ditimbulkan. Pelanggaranpelanggaran tersebut diantaranya adalah costsharing dan pemberian jumlah obat tidak sesuai resep. Cost-sharing adalah sebuah cara dimana pasien atau peserta JKN diminta untuk membayar selisih antara harga obat yang tertera pada e-catalogue dengan harga obat yang diberikan oleh distributor. Hal lain yang juga dilakukan adalah dengan memberikan jumlah obat yang tidak sesuai resep guna menutupi selisih harga tersebut.

Untuk penyediaan terjadi peningkatan jumlah obat yang cukup signifikan, yaitu mencapai 2-3x lipat dari sebelum bergabung dengan BPJS Kesehatan. Peningkatan jumlah pemesanan tersebut dilakukan untuk menyesuaikan dengan peningkatan permintaan obat. Selain itu, apotek melakukan pemesanan yang banyak untuk berjaga-jaga agar tidak terjadi kekosongan stok obat di apotek dikarenakan waktu pemesanan obat yang lama. Hal lain terkait penyediaan obat adalah sering terjadinya kekosongan obat dari distributor. Hal itu terjadi apabila pembelian dilakukan secara e-catalogue. Kekosongan paling lama yang pernah terjadi pada obat adalah obat amlodipine yang mencapai waktu 3 bulan. Selanjutnya, permintaan obat di apotek juga mengalami peningkatan semenjak bekerjasama dengan BPJS Kesehatan. Apotek yang sebelumnya hanya melayani Askes bisa mengalami peningkatan pasien sampai 6x lipat. Hal itu dikarenakan program JKN yang memang bertujuan untuk memberikan jaminan kesehatan untuk seluruh masyarakat Indonesia.

Berbagai hal di atas memberikan pengaruh terhadap ketersediaan obat di apotek rujukan. Secara umum ketersediaan obat di era JKN menimbulkan ketidakpuasan dari peserta program karena tidak lengkap dari segi jenis dan jumlah. Kekosongan obat dari Industri Farmasi pemenang tender maupun sikap PBF yang tidak mau melayani pemesanan obat oleh apotek dengan harga e-catalogue sering menjadi masalah dalam penyediaan obat JKN ini.

Dampak dari ketersediaan obat juga berpengaruh terhadap keuntungan yang didapat oleh apotek. Pada masa awal transisi Askes menjadi JKN apotek sempat menanggung kerugian yang cukup besar. Namun, seiring berjalannya waktu dan perbaikan-perbaikan yang dilakukan oleh pihak apotek maupun BPJS Kesehatan kerugian tersebut dapat berkurang dan berangsur menjadi keuntungan.

\section{Pembahasan}

Dengan melakukan analisis hasil-hasil temuan penelitian, maka peneliti dapat merumuskan sebuah model teori bernama Adaptation Theory in Ill-prepared Agent, seperti yang tercantum dalam gambar 1 . Sebuah perubahan dapat terjadi pada agen perubahan yang tidak disiapkan untuk menjalani perubahan tersebut. Apabila hal tersebut terjadi, maka agen perubahan tersebut akan mengalami kegagalan untuk beradaptasi dengan perubahan yang ada. Sebaliknya, agen perubahan tersebut akan mampu beradaptasi, apabila memiliki keinginan untuk belajar menyesuaikan dengan perubahan yang ada, serta didukung oleh sumber daya, seperti sumber daya manusia, materi, dan informasi.

Perubahan sistem pembiayaan kesehatan dapat berdampak pada apotek yang belum disiapkan untuk berubah. Apotek akan mampu beradaptasi apabila memiliki komitmen untuk terus belajar dan memiliki sumber daya yang memadai. Sebaliknya, apabila tidak memiliki kedua hal tersebut, apotek akan gagal beradaptasi dengan program JKN atau memutuskan kontrak dengan BPJS Kesehatan.

Kesiapan sebuah organisasi menjadi faktor penting yang menentukan keberhasilan sebuah 
perubahan. ${ }^{4-6}$ Teori mengenai kesiapan organisasi telah disampaikan oleh Weiner, yang menyatakan bahwa kesiapan organisasi untuk sebuah perubahan terdiri dari 2 hal, yaitu perubahan komitmen dan perubahan efektifitas. ${ }^{7}$ Perubahan komitmen dapat diartikan bahwa setiap unsur yang terlibat dalam sebuah perubahan harus mengerti akan pentingnya perubahan itu sendiri. Sehingga setiap agen perubahan memiliki motivasi untuk menjalani sebuah perubahan. Hal tersebut perlu diiringi oleh perubahan efektivitas, yaitu bagaimana melakukan manajemen sumber daya yang ada, termasuk sumber daya manusia, keuangan, materi, dan informasi. ${ }^{8}{ }^{9}$ Faktor lain yang juga memengaruhi kesiapan organisasi untuk melakukan adalah kondisi kontekstual. Suasana lingkungan kerja yang kondusif, pengalaman yang positif dalam mengalami perubahan, serta fleksibilitas aturan atau prosedur dalam organisasi turutmembantumeningkatkankesiapan organisasi dalam melakukan perubahan. ${ }^{10}$ Sebuah reformasi sistem kesehatan perlu disertai dengan perubahan control knobs, yang terdiri dari pembiayaan (financing), pembayaran (payment), organisasi (organization), regulasi (regulation), dan perilaku (behavior). ${ }^{l l}$ BPJS sebagai pelaksana program seharusnya memerhatikan kelima aspek tersebut dalam implementasi program JKN. Kelima aspek tersebut harus diawasi secara seimbang, sehingga dapat meminimalisasi kemungkinan terjadinya kerugianyang ditimbulkandariperubahanyangada

Perubahan sistem pembiayaan kesehatan merupakan langkah besar yang dilakukan oleh pemerintah Republik Indonesia. Sayangnya, hal tersebut tidak disertai dengan persiapan sektor pemerintah dalam hal ini BPJS Kesehatan dan sektor swasta (apotek) serta komitmen yang kuat dalam menjalankan program JKN. Apabila dilihat dari teori Control Knobs, masalah yang timbul merupakan manifestasi dari knop pembayaran, organisasi, regulasi, dan perilaku. Perubahan sistem pembiayaan kesehatan menuntut apotek atau pihak yang terkait melakukan perubahan untuk menyesuaikan dengan sistem yang ada. Perubahan tersebut perlu didukung oleh sumber daya, baik itu sumber daya manusia, barang, maupun modal. Apabila hal tersebut mampu dipenuhi oleh suatu apotek maka apotek tersebut akan mampu beradaptasi dengan perubahan yang ada. Sebaliknya, apabila tidak ada usaha yang dilakukan untuk melakukan penyesuaian, apotek tersebut akan mengalami kegagalan dalam beradaptasi. Keterbatasan penelitian ini terdapat pada jumlah terwawancara yang berjumlah 8 orang. Pihak yang dianggap dapat memberikan informasi terkait ketersediaan obat namun belum bisa dilibatkan dalam penelitian ini adalah manajemen rumah sakit dan PBF atau distributor obat.

Kesimpulan dari dampak perubahan sistem pembiayaan kesehatan terhadap ketersediaan obat di apotek rujukan wilayah Cibeunying, adalah: Apotek masih mengalami hambatan dalam penyediaan obat fornas disebabkan kesulitan mendapatkan obat dengan e-catalogue dari Industri Farmasi sehingga obat kadang-kadang kosong atau apotek terpaksa membeli dari pihak lain dengan harga normal. Selain itu lamanya mendapatkan klaim dan penolakan terhadap klaim obat karena ketidak lengkapan persyaratan yang disebabkan informasi BPJS yang terlambat menjadi faktor yang cukup merugikan pihak apotek; Peserta BPJS merasa dirugikan karena tidak mendapatkan obat denganjumlahyang sesuai atau harus membayar sebagian harga obat karena kebijakan apotek untuk cost-sharing; Kesiapan

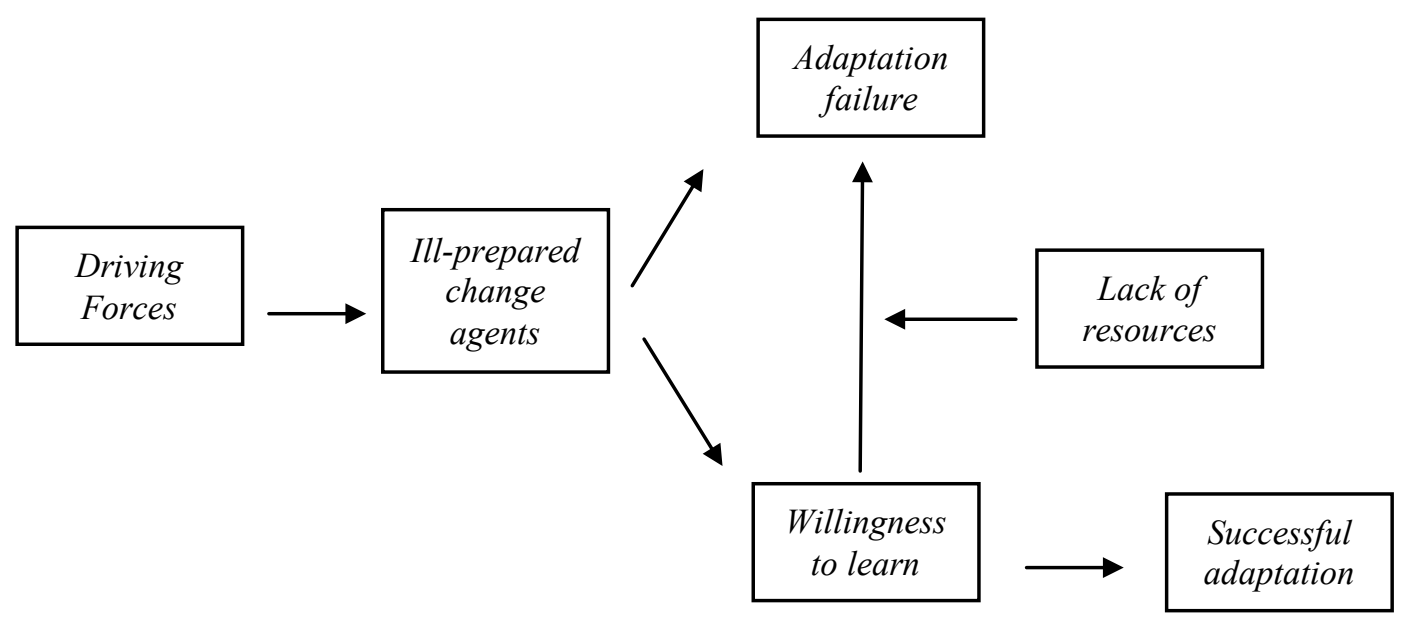

Gambar 1 Adaptation Theory in Ill-prepared Agent 
semua pihak yang terkait harus ditingkatkan yaitu BPJS Kesehatan - Industri Farmasi apotek jejaring demi kepuasan peserta JKN.

Berdasarkan kesimpulan di atas, peneliti memberikan saran untuk BPJS kesehatan melakukan evaluasi terhadap alur pemberian informasi mengenai JKN, guna meminimalisasi terjadinya keterlambatan informasi, dan BPJS Kesehatan melakukan peninjauan kembali kontrak yang telah dibuat dengan pihak-pihak yang terkait, seperti apotek dan Industri Farmasi termasuk PBF, guna meminimalisasi kerugian yang ditimbulkan akibat pelanggaran peraturan.

\section{Daftar Pustaka}

1. Kementerian Kesehatan Republik Indonesia. Buku Pegangan Sosialisasi Jaminan Kesehatan Nasional (JKN) dalam Sistem Jaminan Sosial Nasional. 2013.

2. Putra RS. Malangnya Nasib Peserta BPJS Pada Era JKN2014. Available from:http://kesehatan.kompasiana.com/ medis/2014/06/20/malangnya-nasibpeserta-bpjs-pada-era-jkn-663298.html.

3. Schwandt TA, Lincoln YS, Guba EG. Judging interpretations: But is it rigorous? trustworthiness and authenticity in naturalistic evaluation. New Directions for Evaluation. 2007;2007(114):11-25.
4. Amatayakul M. EHR? Assess readiness first. Healthc Financ Manage. 2005;59:112 - 3. 5. Kirch D, Grigsby R, Zolko W, Moskowitz J, Hefner D, Souba W, et al. Reinventing the academic health center. Acad Med. 2005;80:980 - 9.

6. O'Connor E, Fiol C. Creating readiness and involvement. Physician Exec. 2006;32:72 - 4.

7. Weiner B. A theory of organizational readiness for change. Implementation Science. 2009;4(1):67.

8. Weiner B, Lewis M, Linnan L. Using organization theory to understand the determinants of effective implementation of worksite health promotion programs. Health Educ Res. 2009;24:292 - 305.

9. Weiner B, Amick H, Lee S. Conceptualization and measurement of organizational readiness for change: a review of the literature in health services research and other fields. Med Care Res Rev. 2008;65:379 - 436.

10. Jones $\mathrm{R}$, Jimmieson $\mathrm{N}$, Griffiths A. The Impact of Organizational Culture and Reshaping Capabilities on Change Implementation Success: The Mediating Role of Readiness for Change. Journal of Management Studies. 2005;42:361 - 86.

11. Roberts M, Hsiao W, Berman P, Reich M. Getting health reform right: a guide to improving performance and equity: Oxford university press; 2008. 